
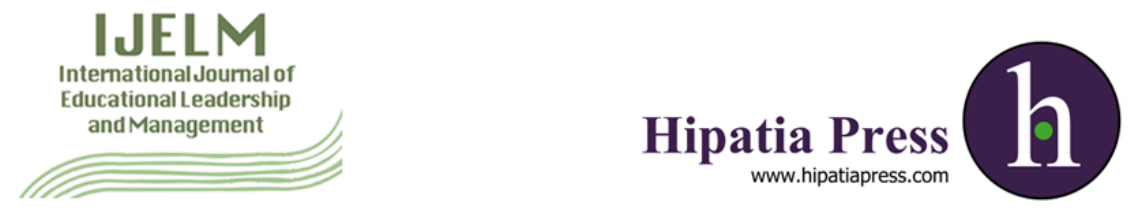

Instructions for authors, subscriptions and further details:

http://ijelm.hipatiapress.com

\title{
School Leadership, Citizenship Education and Politics in China
}

\section{Ana Burgués ${ }^{1}$}

1) Universidad de Barcelona

Date of publication: July $16^{\text {th }}, 2017$

Edition period: July 2017-December 2017

To cite this article: Burgués, A. O. (2017). School Leadership, Citizenship Education and Politics in China. [Review of the book: School Leadership, Citizenship Education and Politics in China]. IJELM, 5(2), 216-217. doi: 10.17853/ijelm.2017.2631

To link this article: http://dx.doi.org/10.17583/ijelm.2017.2867

\section{PLEASE SCROLL DOWN FOR ARTICLE}

The terms and conditions of use are related to the Open Journal System and to Creative Commons Attribution License (CC-BY). 


\section{Review}

Xu, S. (2016). School Leadership, Citizenship Education and Politics in China. Rotterdam: Sense Publishers. ISBN: 2365-6263

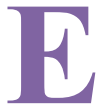

ste libro permite aproximarnos a la realidad en China sobre el liderazgo escolar, la educación por la ciudadanía y la política. Teniendo en cuenta el papel de la globalización, se abordan cuestiones que van más allá del ámbito educativo para explorar sus sinergias con ámbitos diversos, desde la economía o la política pública. Se parte del papel que tiene la educación en aspectos de justicia social y por tanto, se identifica la importancia de promover una educación que incorpore esa dimensión.

En los primeros capítulos, la autora contextualiza y nos acerca de forma rigurosa y clara a los debates sobre liderazgo escolar en China, la integración de la educación y la política en ese país, el contexto social y educativo de Shangai o su sistema de liderazgo escolar. A continuación, se indican cuatro escenarios posibles sobre las percepciones y respuestas de los líderes escolares a las políticas estatales y sus requerimientos, que se resumirían en: aceptación activa, aceptación pasiva, modificación de apoyo y modificación de no apoyo. Las consecuencias para la práctica de cada uno de estos escenarios se desarrollan de manera precisa, permitiendo al lector tener una aproximación y conocimiento muy útiles. En los capítulos finales, se plantean algunos retos sobre el liderazgo escolar y educación por la ciudadanía, haciendo hincapié en su rol como ejercicio político. 
En resumen, la autora identifica a través de su trabajo que los líderes escolares ejercen un papel activo en respuesta a los actores escolares macro y micro-políticos. Además, sugiere futuras líneas y temáticas de investigación a partir de su trabajo para continuar investigando en las sinergias entre la educación por la ciudadanía y el liderazgo escolar. Sin duda, abre posibilidades para desarrollar próximas contribuciones en el contexto de Shangai.

Ana Burgués, Universidad de Barcelona 